\title{
Facing a trend of brand logo simplicity: The impact of brand logo design on consumption
}

Citation for published version (APA):

Bossel, V., Geyskens, K., \& Goukens, C. (2019). Facing a trend of brand logo simplicity: The impact of brand logo design on consumption. Food Quality and Preference, 71, 129-135. [71].

https://doi.org/10.1016/j.foodqual.2018.06.009

Document status and date:

Published: 01/01/2019

DOI:

10.1016/j.foodqual.2018.06.009

Document Version:

Publisher's PDF, also known as Version of record

Document license:

Taverne

Please check the document version of this publication:

- A submitted manuscript is the version of the article upon submission and before peer-review. There can be important differences between the submitted version and the official published version of record.

People interested in the research are advised to contact the author for the final version of the publication, or visit the DOI to the publisher's website.

- The final author version and the galley proof are versions of the publication after peer review.

- The final published version features the final layout of the paper including the volume, issue and page numbers.

Link to publication

\footnotetext{
General rights rights.

- You may freely distribute the URL identifying the publication in the public portal. please follow below link for the End User Agreement:

www.umlib.nl/taverne-license

Take down policy

If you believe that this document breaches copyright please contact us at:

repository@maastrichtuniversity.nl

providing details and we will investigate your claim.
}

Copyright and moral rights for the publications made accessible in the public portal are retained by the authors and/or other copyright owners and it is a condition of accessing publications that users recognise and abide by the legal requirements associated with these

- Users may download and print one copy of any publication from the public portal for the purpose of private study or research.

- You may not further distribute the material or use it for any profit-making activity or commercial gain

If the publication is distributed under the terms of Article $25 \mathrm{fa}$ of the Dutch Copyright Act, indicated by the "Taverne" license above, 


\title{
Facing a trend of brand logo simplicity: The impact of brand logo design on consumption
}

\author{
Vera Bossel, Kelly Geyskens*, Caroline Goukens \\ Maastricht University, Department of Marketing and Supply Chain Management, Tongersestraat 53, 6211 LM Maastricht, The Netherlands
}

\section{A R T I C L E I N F O}

\section{Keywords:}

Brand logo

Simple design

Consumption

Processing fluency

Prestige

Food intake

\begin{abstract}
A B S T R A C T
Research has shown that the experience of fluency influences buying intentions of food products, but no study has examined how brand logos transferring a feeling of fluency might impact actual food intake. In two experiments, we assess how exposure to simple versus complex brand logos impacts food consumption. Study 1 shows that individuals consume more from a product which features a simple, flat logo compared to a product that features a complex, non-flat logo. Study 2 depicts the nature of the product as an important moderator in this effect: while for non-prestigious products simple brand logos increase consumption, the opposite occurs for prestigious food products. Overall, while the tenet of the findings is consistent with earlier work on fluency effects within the food domain, this research provides evidence that brand logo design has the potential to impact actual food intake.
\end{abstract}

\section{Introduction}

Millions of people are struggling with controlling their food consumption (Haws \& Redden, 2013) and rising obesity rates suggest that the struggle is real. Indeed, since 1975 the number of overweight and obese people worldwide has nearly tripled, with globally approximately 1.9 billion overweight adults in 2016 (World Health Organization, 2017). One reason why the struggle against obesity is such a difficult one is the fact that unobtrusive factors not openly related to consumption wield an unnoticed influence on consumption patterns. Product design factors such as product size (e.g., Rolls, Roe, Kral, Meengs, \& Wall, 2004; Coelho et al., 2008), product shape (e.g., van Ooijen, Fransen, Verlegh, \& Smit, 2016; Huyghe, Geuens, \& Vermeir, 2017), and product labels (e.g., Finkelstein \& Fishbach, 2010; Mullie, Godderis, \& Clarys, 2012; Vadiveloo, Morwitz, \& Chandon, 2013) have been repeatedly found to significantly alter food intake. Yet, at the same time, these "hidden" factors also present a way to regulate consumption styles. In fact, micro-changes in the consumer landscape might even present a possible route to a healthy lifestyle.

The current research focuses on a prominent product design feature, namely the brand logo design, and it's potential to influence food intake. Certainly, brand logo design may have multiple downstream effects (e.g., on brand awareness, aided recognition, and buying intention; Chevalier \& Mazzalovo, 2003; Henderson \& Cote, 1998; Pocheptsova, Labroo, \& Dhar 2010), yet the aim of this research is to understand whether the specific design features of a brand logo can influence food intake.

Notably, and partly the inspiration of this research, is the trend of brand logo simplification. Numerous major brands including Starbucks, Nesquik, Subway, and Pepsi (cf. Fig. 1) have redesigned their logos opting for a more simplistic look. This simplification is a token of flat design, a trend characterized by a focus on simple and minimalistic design (Clum, 2013). This trend is in line with a growing body of scientific literature in the domain of processing fluency, which clearly shows that a fluent processing of stimuli leads to more positive evaluations (Reber, Schwarz, \& Winkielman, 2004; Schwarz, 2004; Winkielman, Schwarz, Fazendeiro, \& Reber, 2003; Zajonc, 1968). Logos, just like any other stimuli, can contribute to a feeling of overall processing fluency which signals the "[...] subjective experience of ease with which people process information [...]" (Alter and Oppenheimer, 2009 , p. 219). As such, products featuring flat design are expected to positively influence the attitudes of consumers.

Surprisingly, despite the prevalent trend of brand simplification, prior research has not studied how logo simplification might impact food intake. In this research we put forward the hypothesis that consumers might consume more from products that feature a simple, flat logo than products that feature a more complex, non-flat logo, as the experience of processing fluency facilitates their consumption.

Evidently, the latter will only apply when ease of processing triggers a positive experience. From recent research we know that this logic does not always hold. In fact, research has shown that for prestigious products, increasing disfluency (e.g., by adding a text in a difficult-to-

\footnotetext{
* Corresponding author.

E-mail address: k.geyskens@maastrichtuniversity.nl (K. Geyskens).
} 

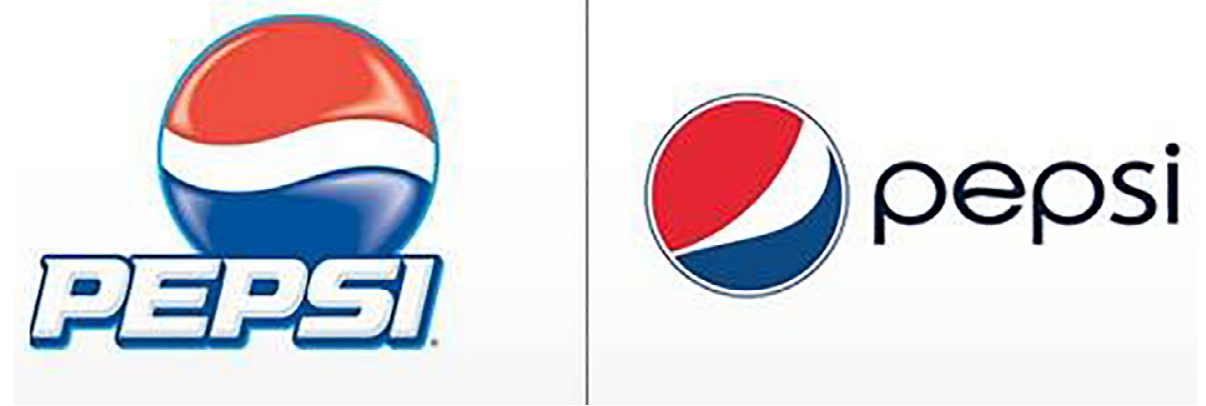

Fig. 1. On the left is the old Pepsi logo. On the right is the redesigned, more simple logo as introduced in 2008.

read font) rather than fluency (e.g., by adding a text written in an easyto-read font) promotes purchase intentions (Pocheptsova et al., 2010). As such, we additionally put forward the hypothesis that the prestigious nature of a particular brand might interfere with the feeling of fluency that a flat design transfers. This implies that consumers would actually consume more of a prestigious food item if it sports a complex logo design and less so if it sports a simple, flat logo design.

Overall, we put forward the proposition that the trend of brand logo simplification might result in increased food intake by consumers, unless the product is seen as being prestigious. As such, opting for flat design to permeate an entire branding strategy may not be such a good idea for a brand. Rather, to facilitate the consumption experience, one should consider adapting the brand logo design to the specific nature of the product.

\section{Theoretical framework and hypotheses}

Processing fluency is a ubiquitous phenomenon: Every stimulus is imbued with a processing fluency cue, which ranges from easy-to-process (fluent) to difficult-to-process (disfluent). This metacognitive cue accompanies one's thought processes, often without one's explicit awareness (Schwarz, 2004). For example, in a classic study on processing fluency, Reber, Winkielman, and Schwarz (1998) showed that fluent circles, namely circles presented on highly contrastive backgrounds, were judged to be prettier than the same circles presented on a less contrastive background.

By now processing fluency research has amassed a large number of studies, linking insights from social psychology and consumer behavior research. The majority of processing fluency research attests positive effects to fluent stimuli: It has been evidenced that people judge fluent stimuli as more favorable (Lee \& Labroo, 2004), more true (Reber \& Schwarz, 1999; Skurnik, Yoon, Park, \& Schwarz, 2005), more confident (Alter, Oppenheimer, Epley, \& Eyre, 2007), more intelligent (Oppenheimer, 2006), and more familiar (Whittlesea, 1993).

The fact that positive evaluations can be evoked through processing fluency is strongly relevant for the marketing and specifically consumer behavior context. As such, a number of studies have linked processing fluency to product evaluations, demonstrating that consumer products are evaluated more positively if they are perceptually or conceptually fluent (e.g., Berger \& Fitzsimons, 2008; Chae \& Hoegg, 2013, Eelen, Dewitte, \& Warlop, 2013; Gmuer, Siegrist, \& Dohle, 2015; Labroo, Dhar, \& Schwarz, 2007). This relationship can be easily explained from an evolutionary point of view: fluency signals familiarity, a characteristic that was deemed extremely valuable and positive in our early ancestor's environment (Halberstadt \& Rhodes, 2003).

The connection between processing fluency and positive evaluations is well supported in literature, yet surprisingly little processing fluency research has been done in the food domain. One of the few exceptions is research conducted by Pocheptsova et al. (2010) who investigated the effect of experiencing processing fluency on purchase intentions of food products. In this research, participants were found to be more willing to buy from a food product when its picture was accompanied by a descriptive text written in an easy-to-read font, compared to when it was written in a difficult-to-read font. As such, this finding indicates that the experience of fluency, rather than disfluency, enhances buying intention in the food domain.

The aim of this research is to investigate whether processing fluency, as triggered by the brand logo design, impacts actual food consumption. Although one needs to be careful with drawing interferences from purchase intent to actual consumption (Cardello \& Maller, 1982; Cardello, Schutz, Snow, \& Lesher, 2000; Vickers \& Mullan, 1997; Schäufele \& Hamm, 2018), we posit that subjective feelings of fluency, as triggered by logo simplification, will further translate into increased food intake (thus actual consumption volume instead of mere buying intentions). As mentioned before, ample research has demonstrated that increased processing fluency fosters the impression that a stimulus is familiar (e.g., Schwarz, 2004; Song \& Schwarz, 2006), which had highly positive associations in our early ancestor's environment (Halberstadt \& Rhodes, 2003). Individuals are indeed biologically predisposed to act with caution in encounters with novel, and thus potentially harmful, stimuli (Zajonc, 1998). The latter is extremely relevant in a food context, as is demonstrated by empirical evidence describing the initially sceptic and anxious reactions by consumers when encountering unfamiliar food (e.g., Fenko, Leufkens, \& van Hoof, 2015; Fisher \& Frewer, 2009; Siegrist, Hartmann, \& Keller, 2013). As such, increasing the familiarity of the food, for example by repeated exposure (Maier, Chabanet, Schaal, Issanchou, \& Leathwood, 2007), or by involvement in its preparation (van der Horst, Ferrage, \& Rytz, 2014) has been found to increase food intake.

To some extent, this reasoning is consistent with the idea that food intake is facilitated if an optimal level of stimulation is not exceeded (Levy, MacRae, \& Koster, 2006), as evinced by findings showing increased food intake by individuals who are accompanied by familiar (vs. unfamiliar) co-eaters (Salvy, Vartanian, Coelho, Jarrin, \& Pliner, 2008), who simultaneously watch familiar (vs. novel) TV-shows (Mathur, \& Stevenson, 2015), or who are simultaneously stimulated with simple (vs. complex) aromas (Ruijschop, Boelrijk, Burgering, deGraff, \& Westerterp-Plantenga, 2010). Overall, we thus expect that food products featuring a simple, flat (vs. complex) design will facilitate consumption and increase food intake.

Hence we hypothesize

H1. Consumption volume is larger for a snack item featuring a simple, flat brand logo than for a snack item featuring a complex logo.

Although processing fluency has been described exerting a positive influence on product attitudes (Alter \& Oppenheimer, 2009; Schwarz, 2004; Schwarz, Song, \& Xu, 2009), more recent research suggests that this effect might be moderated by the nature of the product. As outlined above, the positive relationship between fluency and liking can be attributed to a feeling of familiarity with the object (Lee, 2001). However, 
in the context of prestigious food products, for which consumers rather value exclusivity (instead of familiarity), processing fluency triggers opposite effects, and thus decreases product attitudes and buying intentions (Pocheptsova et al., 2010). Within our research, we therefore incorporate the nature of the product and investigate whether product prestige (i.e., basic versus prestigious) moderates the effect of brand logo simplicity on consumption volume. That is, we expect logo simplicity to increase the food intake of basic, everyday products, but to decrease the food intake of prestigious food products.

Hence, we hypothesize:

H2. Product prestige moderates the relationship between brand logo simplicity and consumption volume.

To the best of our knowledge, this research is the first to investigate the downstream consequences of brand logo simplification on food intake. Inspired by prior research showing that experienced fluency impacts consumption intentions (through the measurement of buying intentions), this research explicitly tests how brand logo simplicity might impact actual food intake. We furthermore investigate product prestige as a potential moderator of the effect.

A brand logo is an important feature of a product design in attracting a consumer's attention (e.g., Piqueras-Fiszman, Velasco, Salgado-Montejo, \& Spence, 2013). It is often a salient feature on a product package, and is in some cases even printed on the product itself (e.g., M\&Ms). As such, consumers are frequently exposed to the brand logo while consuming the product. Given this frequent exposure to brand logos, with flat design marking a clear trend in favor of simple, fluent brand logos, investigating the effects of logo simplicity on consumption presents a timely research issue.

\section{Study 1}

To test the impact of brand logo simplicity on snack consumption we conducted a lab experiment during which participants were asked to participate in a taste test. During this taste test, participants were either exposed to a simple logo, a complex logo, or no logo.

To pretest the simplicity of various logos, we asked 94 participants to evaluate a number of novel logo symbols. We adopt Henderson and Cote's (1998) definition of visual complexity, which is marked by cooccurrence of five complexity elements: bevels, gradients, rotation, drop shadows, and reflections. This allowed us to quantify the level of logo complexity. A simple logo has none of those elements while a complex logo features all elements at once. Based on these elements, we selected two logos (a simple and a complex logo). These were rated as significantly different in terms of simplicity on a scale from 1 (simple) to 7 (complex): $M_{\text {simple }}=1.78(S D=0.94), M_{\text {complex }}=5.5(S D=1.4)$, $F(1,91)=35.92, p<.05$ (Fig. 2).

\subsection{Method}

\subsubsection{Participants}

A total of 201 undergraduate students from a large western European university participated in the study in exchange for course credit. After an outlier analysis we excluded 27 participants whose
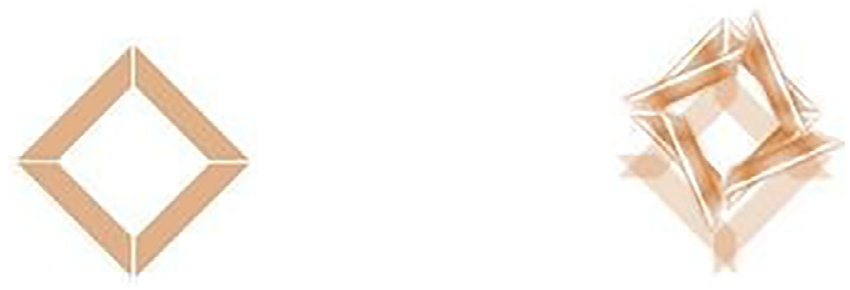

Fig. 2. Logos used in study 1: the simple logo on the left, the complex logo on the right. score was either $3 S D$ s above the mean $(n=17)$ or who did not consume $(n=10)$. This leaves a total sample size of 174 participants (105 females, $M_{\text {age }}=22.7, S D=2.6$ ). All participants were asked to participate in a taste test. A 'bogus' taste test is a widely employed and valid method to measure food intake in an unobtrusive manner (Robinson et al., 2017). Participants were randomly assigned to the "no logo", "simple logo", or "complex logo" condition. Original data of this study are available at Mendeley Data (http://dx.doi.org/10.17632/ v94dzt3yz3.1).

\subsubsection{Procedure}

Participants were invited to the university lab. Upon entering the lab, each participant and no more than 12 at a time were seated in separate cubicles. All were informed that they would be participating in a taste test of a new type of chocolate snack, Lotus $^{\circledR}$ Speculoos Rolls. This product serves the purpose of a bogus taste test well since its form and taste are novel enough to pass for a new product, without being too special which may skew results. In fact, speculoos flavor is a common staple among snack items. A one-sample $t$-test in which 53 respondents indicated their prestige perceptions of the product on a likert scale from 1 to 9 (1: unprestigious/low quality - 9: prestigious/high quality), showed that the image of the speculoos rolls was considered neither low nor high quality but fairly average instead $\left(M_{\text {prestige perception }}=5.40\right.$, $S D=2.13, \quad t(52)=1.35, \quad p=.18$ and $M_{\text {quality }}$ perception $=5.23$, $S D=1.95, t(52)=0.85, p=.40)$.

For the purpose of the study, each participant received a white ceramic bowl containing $300 \mathrm{~g}$ of the product (approximately 100 pieces). We chose this amount to avoid that participants can infer how much they have eaten from the bowl, as this feedback may influence their consumption (Polivy, Herman, Hackett, \& Kuleshnyk, 1986). Depending on the condition, a simple versus a complex versus no logo was attached to the bowl. To strengthen our cover story, the taste test was accompanied by a survey that asked respondents to indicate their evaluation of the product on various items (e.g., general liking of the taste of the product, crunchy, hard to resist,...) by means of a 9-point scale. Participants were reassured that they could eat as much of the product as they want.

Additionally, participants were asked to indicate their impressions of the logo on the following dimensions: simplicity, familiarity, conveyed quality, and expensiveness on a 7-point semantic differential scale. We also assessed the logo aesthetics (i.e., likeability, attractiveness, prettiness, and noticeability; $\alpha=0.87$ ). Additionally we measured the extent to which the logo was seen as harmonious, inviting, and appropriate for the specific product, on a scale from 1 (not at all) to 9 (very much). At the end of the questionnaire, we measured hunger level (i.e., Please indicate how hungry you were before you started the taste test, 1 (not at all) to 6 (to a very large extent)), restraint (i.e., the Restraint Scale; Polivy, Herman, \& Howard, 1988), age, and gender. Once all participants were dismissed from the lab, their bowls were weighed and consumption volume was recorded.

\subsection{Results}

The manipulation check was successful: Participants deem the simple version of the logo to be more simple $\left(M_{\text {simple }}=2.4, S D=1.4\right)$ than the complex logo $\left(M_{\text {complex }}=4.1, S D=1.6\right): t\left(\begin{array}{ll}1 & 15\end{array}\right)=-5.89$, $p<.001$. Moreover, results show that there is no significant difference between the simple and complex logo in terms of familiarity, conveyed quality, and aesthetics, all $p>.30$. There is a marginally significant difference in terms of perceived expensiveness $\left(M_{\text {simple }}=3.13\right.$, $S D=1.34, M_{\text {complex }}=3.62, S D=1.43, p=.06$ ). Though, including this item in the main analyses does not affect the results. We found no significant difference in terms of how harmonious, suitable and inviting the logo was perceived; all $p>.60$.

Taste is not influenced by processing fluency. Participants in all three conditions liked the taste of the product equally $\left(M_{\text {simple }}=3.02\right.$, 
$S D=1.34, M_{\text {complex }}=3.17, S D=1.49, \quad M_{\text {control }}=2.91, S D=1.09$, with 1 (extremely like) - 9 (extremely dislike), $F(2,171)<1$ ). Preliminary analyses show that the extent to which they liked the taste of the Speculoos Rolls and hunger are the only control variables that significantly affect the consumed amount and are therefore kept in the analysis as covariates. An ANCOVA with the logo condition as independent variable and general taste liking and hunger as covariates shows a significant main effect on the consumed amount, $F(2$, $169)=3.64, p<.05$. Specifically, participants consume significantly more of the product if it features a simple logo as opposed to a complex logo: $M_{\text {simple }}=20.6, S D=17.5, \quad M_{\text {complex }}=14.8, S D=11.0 \quad(F(1$, $169)=5.29, p<.05)$. Participants also consume significantly more from the product if it sports a simple logo symbol compared to no logo: $M_{\text {simple }}=21.6, \quad S D=17.5, \quad M_{\text {control }}=14.4, \quad S D=11.7 \quad(F(1$, $169)=5.91, p<.05)$. The difference between the control and the complex logo condition is not significant $(F(1,169)<1)$. Hence we can conclude that the effect is driven by the simple logo condition, and that participants eat above baseline level in the presence of a simple logo.

In sum, study 1 confirms our hypothesis and shows that brand logo characteristics have the potential to affect actual food intake: Individuals eat more from a snack that features a simple logo, compared to the same snack featuring a complex, or no brand logo. However, as outlined in the theoretical overview, we expect this effect to only hold for basic, non-prestige products. For prestigious, exclusive products, we expect brand logo complexity to be better suited for signaling the exclusivity of the product, which should enhance food intake.

\section{Study 2}

To test the moderating influence of product prestige in the effect of brand logo simplicity on food intake, we opted for a 2 (logo: simple versus complex) $\times 2$ (product prestige: low versus high) design. Logo simplicity was manipulated by using the same logos that were designed and pretested in study 1 . The prestige level of the chocolates was manipulated by varying the product name. We use the name 'Coquet' for a prestigious product, for a basic product we use the name 'Mibo'. A pretest $(n=47)$ was conducted to select appropriate names. In this pretest, participants were asked to rate the sound of six brand names on a scale from 0 to 100 (0: low prestige, 100: high prestige). Three brand names had a prestigious ring to them ('Coquet', 'Pallet' and 'Triviall') while the other three featured a basic, non-prestigious name ('Mibo', 'Kelly' and 'Dina'). A one-way repeated measures ANOVA reveals that there are significant differences among the six brand names: $F(5$, $42)=7.97, p<.001$. Post-hoc tests with a Bonferroni correction show that the chosen brand names significantly differ in terms of prestige perceptions: 'Coquet' was deemed significantly more prestigious than 'Mibo': $M_{\text {Coquet }}=59.6, \quad S D=27.1, \quad M_{\text {Mibo }}=34.3, \quad S D=24.4, \quad F(1$, $46)=34.91, p<.0001)$. See Fig. 3 for all four logo conditions of study 2.

\subsection{Method}

\subsubsection{Participants}

For this study we recruited a total of 155 undergraduate students from a large western European university to participate in the study in exchange for course credit. After an outlier analysis we excluded participants whose score was either $3 S D$ s above or below the mean $(n=3)$ or who did not consume $(n=1)$. This leaves a total sample size of 151 participants (67 females, $M_{\mathrm{age}}=19.1, S D=1.6$ ). To test whether the effect of logo simplicity differs depending on the perceived prestige of the product, we created a 2 (logo: simple versus complex) $\times 2$ (product prestige: low versus high) design with four conditions, to which participants were randomly assigned. Original data of this study are available at Mendeley Data (http://dx.doi.org/10.17632/chxktwftsg.1).

\subsubsection{Procedure}

Participants were invited to the university lab and informed that they would take part in a taste test. The same procedure and materials as in study 1 were applied, except for the product. Specifically, we used Callebaut ${ }^{\circledR}$ Marble Chocolate pearls. This product is well suited for the intended prestige manipulation, as this product can plausibly be positioned as a prestigious or basic product. Thus, participants in all four conditions received a bowl filled with $500 \mathrm{~g}$ Callebaut ${ }^{\circledR}$ Marble Chocolate Pearls.

The logo corresponding to the condition (cf. Fig. 3) was attached to the bowl. As in study 1, participants were asked to answer a series of questions concerning the taste of the product. Also, participants were reassured that they could eat as much as they want from the product. Similar to study 1 , we asked respondents a few questions about the logo attached to the bowl. That is, we assessed their perceptions on the logo's simplicity, familiarity, conveyed quality, expensiveness, and aesthetics (likeability, attractiveness, prettiness, noticeability; $\alpha=0.85$ ), on a 7-point semantic differential scale. Participants also rated the extent to which the logo/brand name were considered as harmonious, inviting, and suitable for the product, on a scale from 1 (not at all) to 9 (very much). As in study 1, hunger level, restraint, age and gender were measured at the end of the questionnaire. Once all participants were dismissed from the lab, the bowls with the remaining chocolate pearls were carefully weighed and consumption volume was recorded.

\subsection{Results}

The manipulation check was successful: Participants deem the simple version of the logo to be more simple $\left(M_{\text {simple }}=2.2, S D=1.2\right)$ than the complex logo $\left(M_{\text {complex }}=3.9, S D=1.7\right): F(1,147)=52.71$, $p<.0001$. Furthermore, as in study 1 , there are no differences in terms of familiarity, conveyed quality, expensiveness, and aesthetics; all $p>.10$. Additionally we found no significant differences in terms of how harmonious, suitable and inviting the logo/brand name are perceived; all $p>.1$. We also found no difference among the logo groups in terms of participants' taste likings $\left(M_{\text {simple }}=3.02, S D=1.34\right.$, $M_{\text {complex }}=3.17, S D=1.49, M_{\text {control }}=2.91, S D=1.09$, on a scale from 1 (extremely like) to 9 (extremely dislike), $F(1,147)=1.17, p=.28$ ). The interaction effect between logo and product prestige was also not significant $(F(1,147)<1)$.

Preliminary analyses show that the extent to which participants liked the taste of the chocolates and hunger are the only control variables that significantly affect the consumed amount and are therefore kept in the analysis as covariates. Results of a 2 (logo: simple versus complex) $\times 2$ (product prestige: low versus high) between-subjects ANCOVA with general taste liking and hunger as covariates, reveal a significant interaction between logo and product prestige: $F$ $(1,145)=6.63, p<.05$. A simple contrast analysis shows additional partial support of $\mathrm{H}_{1}$; the main effect of logo is marginally significant. Specifically, participants eat more of the basic, low prestige product when it features a simple logo compared to a complex logo: $M_{\text {simple logo- }}$ low prestige $=16.7, S D=15.5, M_{\text {complex logo-low prestige }}=12.09, S D=9.2$, $(F(1,145)=2.81, p=.096)$. For a high prestige product we find a marginally significant effect in the opposite direction: Participants eat more of the product when it features a complex as opposed to a simple logo: $M_{\text {simple logo-high prestige }}=15.9, S D=14.2, M_{\text {complex logo-high pres- }}$ tige $=22.2, S D=15.4 ; F(1,145)=3.82, p=.053$. The effect of logo simplicity seems thus to depend on the perceived prestige of the product featuring the logo.

\section{General discussion}

\subsection{Theoretical and practical contributions}

Logo simplicity seems to be a popular trend, evidenced by the 

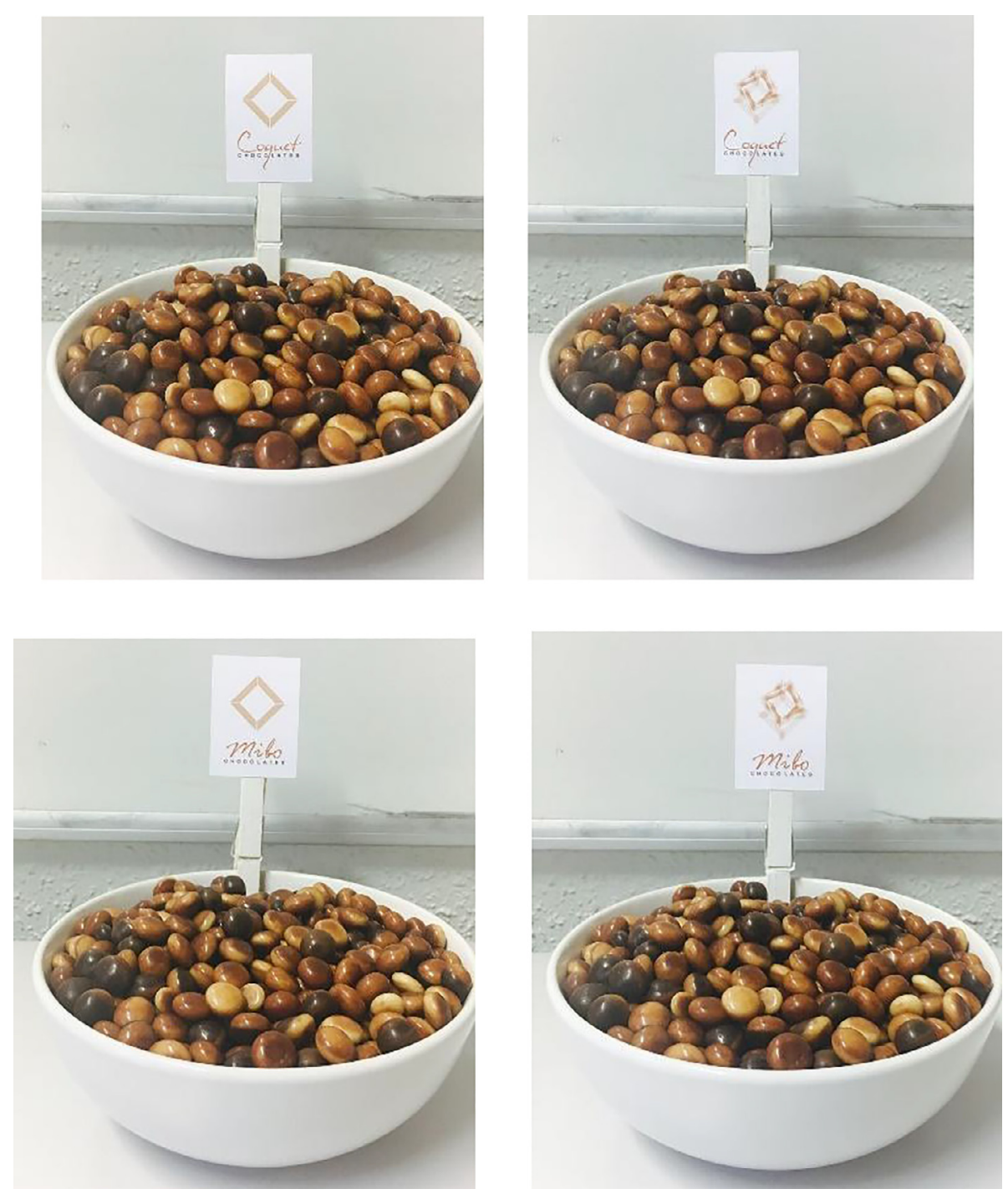

Fig. 3. The four logo conditions used in study 2 as they were presented to the participants.

omnipresent flat design style. Indeed, extant research has shown that simple shapes which are deemed attractive are associated with a fluent processing style (Reber et al., 1998, Tuch, Presslaber, Stöcklin, Opwis, \& Bargas-Avila, 2012). However, to date, only a handful of studies show direct downstream behavioral effects associated with processing fluency, while no study has done so in a consumption context.

The results from our studies show that the original fluency tenet holds true: For everyday products, a simple, flat (vs. complex) design seems to facilitate consumption. As such, we extend previous research (Pocheptsova et al., 2010) with two primary new insights. First, we demonstrate that processing fluency not only influences product evaluations and purchase intentions, but that it also translates into corresponding action. By relying on actual behavioral consumption, we are able to provide evidence that processing fluency affects real consumption behavior, and as such impacts all components in the attitude behavior chain (Fishbein \& Ajzen, 1977). Second, our data provide further insight into the differential effects of fluent versus disfluent experiences. As food intake of an everyday basic product did not differ between the control condition and the complex logo condition, we learn that the effect of logo simplicity on food intake, is driven by the simple logo condition. This implies that, for everyday food products, a simple logo may trigger an increase in food intake. The latter is consistent with prior research on olfactory cues (Herrmann, Zidansek, Sprott, \& Spangenberg, 2013) in which a similar pattern was found: While simple scents were able to push sales numbers, the effect of complex scents was not different from the control condition.

Our results furthermore point towards the fact that, contrary to intuitive beliefs by many manufacturers, the trend towards brand logo simplicity may not always work to a firm's benefit. Indeed, the results of study 2 show that product prestige moderates the effect of brand logo simplicity on food intake: While for basic products consumption levels are higher when this product features a simple logo compared to a complex logo, the opposite occurs for products that are perceived as prestigious.

As such, our research findings add to the growing literature that challenges the prevailing assumption that conditions of processing fluency invariably lead to beneficial consequences. Our results point to the fact that the valence of processing fluency is dynamic. Depending on its association (either with a prestigious product or a basic product) simplicity can lead to differential outcomes (consumption increase or decrease).

Besides providing theoretical impetus for processing fluency research, our findings have managerial implications as well. In particular, low frills products would benefit most from clear and simple brand cues that promote fluent processing. Generally, fluency signals familiarity, which is precisely what these types of products are known for. Hence luxury, premium food products would benefit more from complex, disfluent brand cues as this may stimulate consumption. 


\subsection{Future research}

This article provides a first, exploratory step in understanding how brand logo simplification may impact food intake, and calls for further experimental evidence to completely understand the differential effects of logo simplification for basic and prestigious products on consumption, as well as the underlying mechanisms involved. Our findings suggest many avenues for future research.

First, given the exploratory character of this paper, it features only two types of brand logos and one main outcome measure (food intake) in the context of a novel food snack. Hence, further research is necessary to allow the formulation of general recommendations to practitioners. Future research could test a wider variety of brand logos, and thus gain insights into which logo characteristics have the strongest effect. Future research could also test to what extent the effects hold in the context of well-known products, for which familiarity concerns are less relevant.

Second, it should be noted that we did not find differences in taste liking between our conditions. These findings are interesting considering the established link between fluency and affective judgment (i.e., liking) (e.g., Winkielman et al., 2003). Nevertheless, these findings accord with recent research by Westerman, Lanska, \& Olds (2015) showing that in judgement domains where both liking and familiarity are relevant (as when encountering new food stimuli), the positive reaction triggered by fluency does not translate into a subjective experience of liking. Instead, the subjective experience that accompanies the experience of processing fluency is dominated by and attributed to a sense of familiarity. The positive reaction to fluent processing seems thus to be easily overshadowed by a more dominant impression of familiarity. Future work should thus seek to investigate the underlying role of perceived familiarity. Measuring the extent to which simple versus complex logos are able to signal product familiarity to a consumer would illuminate circumstances under which logo design is able to alter food intake. Considering the unconscious nature of fluency effects (Jacoby, Woloshyn, \& Kelley, 1989), we expect logo design complexity to influence implicit measures of familiarity.

Third, additional research could further investigate the nature of the moderation by prestige perceptions. In our theorizing, we rely on previous research by Pocheptsova et al. (2010) in claiming that perceived familiarity, as signaled by the simple, fluent brand logo design, does not fit the exclusive and unique nature of prestige products. As such, a complex logo is better suited for a prestigious product than a simple, fluent logo. Nevertheless, it could as well be that the specific combination of the product nature and the brand logo/name is seen as more congruent, and thus more fluent by participants. That is, the combination of a prestigious product with a disfluent logo might be seen as highly congruent. Likewise, 'Coquet' might be seen as more congruent with the complex logo, and 'Mibo' with the more simple one. Indeed, the degree to which two stimuli match or fit together (i.e., their congruence; Garretson \& Niedrich, 2004), has been shown to significantly affect fluent processing: Congruent stimuli are processed more fluently than incongruent stimuli because they correspond with previously seen or heard images and ideas (Jacoby, Kelley, \& Dywan, 1989). For example, studies have shown that, compared with incongruent advertisements, congruent advertisements are processed more fluently (De Vries \& Van Rompay, 2009; Van Rompay, De Vries, \& Van Venrooij, 2010; van Rompay \& Pruyn, 2011), congruence within marketing mix elements (e.g., a luxurious jewelry manufacturer sponsoring a golf event) is generally desirable (Yorkston \& Menon, 2004), and congruency between political ideology and persuasive appeals influence sustainable behavior through increased perceptual fluency (Kidwell, Farmer, \& Hardesty, 2013). This implies that a congruent product-logobrand name configuration might be perceived as more fluent, eliciting positive affective responses and possibly causing the differences in consumed amount. Although we did not find differences in perceived harmony, suitability, and invitingness between the different brand name-logo configurations, more systematic research is needed to investigate congruency as a possible explanatory mechanism between processing fluency and consumption patterns.

Fourth, in our research we focused solely on unhealthy products. In fact, extant research has largely focused on purchase intentions and consumption patterns of unhealthy snacks such as wine (Gmuer et al., 2015), cheese and chocolates (Pocheptsova et al., 2010). Future research should seek to replicate our findings using healthy products, such as fruits or nuts. Do the positive effects of simplicity hold across product categories varying in healthiness (e.g., grapes versus chocolate)? The results of this type of research would be beneficial in our endeavors to promote healthy eating habits and combat rising obesity rates. If our effects would replicate, then our logo manipulations that lead to increased consumption levels could be applied to healthy food products. Thus, to promote consumption of everyday fruits, such as apples and bananas, one could benefit from the use of simple, fluent logos. More exquisite types of fruits such as Pineapple Guavas or Pitayas could be adorned with a complex label.

Besides validating results across product groups, future research could further investigate this topic by conducting field studies. Like the majority of processing fluency studies, this study was conducted in the lab. Corresponding field studies can enhance the validity of these findings. It would be interesting to investigate to which extent results apply to a naturalistic dining environment (e.g., an upscale restaurant with a menu featuring a simple, fluent versus a complex, disfluent font).

In sum, our research responds to the call for a better understanding on how product manufacturers might influence consumers' food intake through brand logo designs. Our research shows how micro changes and external cues in consumers' immediate environment, for example a brand logo, can act as a driver for consumption volume outside of the consumer's awareness. Furthermore, depending on how a given food product's image is framed, the processing fluency signal gleaned from its brand logo design can either promote or reduce consumption. The insight that simpler does not always equal better can be a powerful tool that can help influence consumption behavior.

\section{Declarations of interest}

None.

The authors ensure that the work described has been carried out in accordance with The Code of Ethics of the World Medical Association (Declaration of Helsinki) for experiments involving humans subjects. Informed consent was obtained by all participants in the experiments. Additionally participants were given the option to receive a debriefing. In all stages of the experiment, the privacy rights of human subjects were observed.

This research did not receive any specific grant from funding agencies in the public, commercial, or not-for-profit sectors.

\section{References}

Alter, A. L., \& Oppenheimer, D. M. (2009). Uniting the tribes of fluency to form a metacognitive nation. Personality and Social Psychology Review, 13(3), 219-235.

Alter, A. L., Oppenheimer, D. M., Epley, N., \& Eyre, R. N. (2007). Overcoming intuition: Metacognitive difficulty activates analytic reasoning. Journal of Experimental Psychology: General, 136(4), 569-576.

Berger, J., \& Fitzsimons, G. (2008). Dogs on the street, pumas on your feet: How cues in the environment influence product evaluation and choice. Journal of Marketing Research, 45(1), 1-14.

Cardello, A. V., \& Maller, O. (1982). Relationships between food preferences and food acceptance ratings. Journal of Food Science, 47(5), 1553-1561.

Cardello, A. V., Schutz, H., Snow, C., \& Lesher, L. (2000). Predictors of food acceptance, consumption and satisfaction in specific eating situations. Food Quality and Preference, 11(3), 201-216.

Chae, B., \& Hoegg, J. (2013). The future looks "right": Effects of the horizontal location of advertising images on product attitude. Journal of Consumer Research, 40(2), 223-238.

Chevalier, M., \& Mazzalovo, G. (2003). Pro logo: Brands as a factor of progress. New York, NY: Springer.

Clum, L. (2013). A Look at Flat Design and Why It's Significant. https://uxmag.com/ 
articles/a-look-at-flat-design-and-why-its-significant Accessed 22.11.2017.

Coelho do Vale, R., Pieters, R., \& Zeelenberg, M. (2008). Flying under the radar: Perverse Package size effects on consumption self-regulation. Journal of Consumer Research, 35(3), 380-390.

De Vries, P., \& Van Rompay, T. J. L. (2009, April). Subtle persuasion: The unobtrusive effect of website-banner congruence on trust. In: Proceedings of the 4th International Conference on Persuasive Technology, Persuasive '09, Claremont, CA.

Eelen, J., Dewitte, S., \& Warlop, L. (2013). Situated embodied cognition: Monitoring orientation cues affects product evaluation and choice. Journal of Consumer Psychology, 23(4), 424-433.

Fenko, A., Leufkens, J., \& van Hoof, J. J. (2015). New product, familiar taste: Effects of slogans on cognitive and affective responses to an unknown food product among food neophobics and neophilics. Food Quality and Preference, 39, 268-276.

Finkelstein, S. R., \& Fishbach, A. (2010). When healthy food makes you hungry. Journal of Consumer Research, 37(3), 357-367.

Fishbein, M., \& Ajzen, I. (1977). Belief, attitude, intention and behavior: An introduction to theory and research. Reading, MA: Addison-Wesley.

Fisher, A. R. H., \& Frewer, L. J. (2009). Consumer familiarity with foods and the perceptions of risks and benefits. Food Quality and Preference, 20(8), 576-585.

Garretson, J. A., \& Niedrich, R. W. (2004). Spokes-characters: Creating character trust and positive brand attitudes. Journal of Advertising, 33(2), 25-36.

Gmuer, A., Siegrist, M., \& Dohle, S. (2015). Does wine label processing fluency influence wine hedonics? Food Quality and Preference, 44, 12-16.

Halberstadt, J., \& Rhodes, G. (2003). It's not just average faces that are attractive: Computer-manipulated averageness makes birds, fish, and automobiles attractive. Psychonomic Bulletin and Review, 10(1), 149-156.

Haws, K. L., \& Redden, J. P. (2013). In control of variety. High self-control reduces the effect of variety on food consumption. Appetite, 69, 196-203.

Henderson, P. W., \& Cote, J. A. (1998). Guidelines for selecting or modifying logos. Journal of Marketing, 62(2), 14-30.

Herrmann, A., Zidansek, M., Sprott, D. E., \& Spangenberg, E. R. (2013). The power of simplicity: Processing fluency and the effects of olfactory cues on retail sales. Journal of Retailing, 89(1), 30-43.

Huyghe, E., Geuens, M., \& Vermeir, I. (2017). To squeeze or not to squeeze: How squeeze tubes affect consumers' serving sizes. Appetite, 111, 56-62.

Jacoby, L. L., Kelley, C. M., \& Dywan, J. (1989). Memory attributions. In H. L. Roediger, \& F. I. M. Craik (Eds.). Varieties of memory and consciousness: Essays in honour of Endel Tulving (pp. 391-422). Hillsdale, NJ: Erlbaum.

Jacoby, L. L., Woloshyn, V., \& Kelley, C. (1989). Becoming famous without being recognized: Unconscious influences of memory produced by dividing attention. Journal of Experimental Psychology: General, 118, 115-125.

Kidwell, B., Farmer, A., \& Hardesty, D. M. (2013). Getting liberals and conservatives to go green: Political ideology and congruent appeals. Journal of Consumer Research, 40(2), 350-367.

Labroo, A. A., Dhar, R., \& Schwarz, N. (2007). Of frog wines and frowning watches: Semantic priming, perceptual fluency, and brand evaluation. Journal of Consumer Research, 34(6), 819-831.

Lee, A. Y. (2001). The mere exposure effect: An uncertainty reduction explanation revisited. Personality and Social Psychology Bulletin, 27(10), 1255-1266.

Lee, A. Y., \& Labroo, A. A. (2004). The effect of conceptual and perceptual fluency on brand evaluation. Journal of Marketing Research, 41(2), 151-165.

Levy, C. M., MacRae, A., \& Koster, E. P. (2006). Perceived Stimulus Complexity and Food Preference Development. Acta Psychologica, 123(November), 394-413.

Maier, A., Chabanet, C., Schaal, B., Issanchou, S., \& Leathwood, P. (2007). Effects of repeated exposure on acceptance of initially disliked vegetables in 7-month old in fants. Food Quality and Preference, 18(8), 1023-1032.

Mathur, U., \& Stevenson, J. R. (2015). Television and eating: Repetition enhances food intake. Frontiers in Psychology, 6, 1657.

Mullie, P., Godderis, L., \& Clarys, P. (2012). Determinants and nutritional implications associated with low-fat food consumption. Appetite, 58(1), 34-38.

Oppenheimer, D. M. (2006). Consequences of erudite vernacular utilized irrespective of necessity: Problems with using long words needlessly. Applied Cognitive Psychology, 20(2), 139-156.

Piqueras-Fiszman, B., Velasco, C., Salgado-Montejo, A., \& Spence, C. (2013). Using combined eye tracking and word association in order to assess novel packaging solutions: A case study involving jam jars. Food Quality and Preference, 28(1), 328-338.

Pocheptsova, A., Labroo, A. A., \& Dhar, R. (2010). Making products feel special: When metacognitive difficulty enhances evaluation. Journal of Marketing Research, 47(6), 1059-1069.

Polivy, J., Herman, C. P., Hackett, R., \& Kuleshnyk, I. (1986). The effects of self-attention and public attention on eating in restrained and unrestrained subjects. Journal of Personality and Social Psychology, 50(6), 1253-1260.

Polivy, J., Herman, C. P., \& Howard, K. (1988). The Restraint Scale: Assessment of dieting pp. In M. Hersen, \& S. Bellack (Eds.). Dictionary of behavioural assessment techniques (pp. 377-380). New York: Pergamon.

Reber, R., Schwarz, N., \& Winkielman, P. (2004). Processing fluency and aesthetic pleasure: Is beauty in the perceiver's processing experience? Personality and Social Psychology review, 8(4), 364-382.

Reber, R., Winkielman, P., \& Schwarz, N. (1998). Effects of perceptual fluency on affective judgments. Psychological Science, 9(1), 45-48.

Reber, R., \& Schwarz, N. (1999). Effects of perceptual fluency on judgments of truth. Consciousness and Cognition, 8(3), 338-342.

Robinson, E., Haynes, A., Hardman, C. A., Kemps, E., Higgs, S., \& Jones, A. (2017). The bogus taste test: Validity as a measure of laboratory food intake. Appetite, 116, 223-231.

Rolls, B. J., Roe, L. S., Kral, T. V., Meengs, J. S., \& Wall, D. E. (2004). Increasing the portion size of a packaged snack increases energy intake in men and women. Appetite, 42(1), 63-69.

Ruijschop, R. M., Boelrijk, A. E. M., Burgering, M. J. M., deGraff, C., \& WesterterpPlantenga, S. (2010). Acute effects of complexity in aroma composition on satiation and food intake. Chemical Senses, 35(2), 91-100.

Salvy, S. J., Vartanian, L. R., Coelho, J. S., Jarrin, D., \& Pliner, P. P. (2008). The role of familiarity on modeling of eating and food consumption in children. Appetite, 50, 514-518.

Schäufele, I., \& Hamm, U. (2018). Organic wine purchase behaviour in Germany: Exploring the attitude-behaviour-gap with data from a household panel. Food Quality and Preference, 63, 1-11.

Schwarz, N. (2004). Metacognitive experiences in consumer judgment and decision making. Journal of Consumer Psychology, 14(4), 332-348.

Schwarz, N., Song, H., \& Xu, J. (2009). When thinking is difficult: Metacognitive experiences as information. In M. Wänke (Ed.). Social Psychology of Consumer Behavior (pp. 201-226). New York: Psychology Press.

Siegrist, M., Hartmann, C., \& Keller, C. (2013). Antecedents of food neophobia and its association with eating behavior and food choices. Food Quality and Preference, 30(2), 293-298.

Skurnik, I., Yoon, C., Park, D. C., \& Schwarz, N. (2005). How warnings about false claims become recommendations. Journal of Consumer Research, 31(4), 713-724.

Song, H., \& Schwarz, N. (2006). If it's difficult to pronounce, it must be risky. Fluency, familiarity, and risk perception. Psychological Science, 20(2), 135-138.

Tuch, A. N., Presslaber, E. E., Stöcklin, M., Opwis, K., \& Bargas-Avila, J. A. (2012). The role of visual complexity and prototypicality regarding first impression of websites: Working towards understanding aesthetic judgments. International Journal of HumanComputer Studies, 70(11), 794-811.

Vadiveloo, M., Morwitz, V., \& Chandon, P. (2013). The interplay of health claims and taste importance on food consumption and self-reported satiety. Appetite, 71, 349-356.

Van der Horst, K., Ferrage, A., \& Rytz, A. (2014). Involving children in meal preparation. Effects on food intake. Appetite, 79, 18-24.

van Ooijen, I., Fransen, M. L., Verlegh, P. W., \& Smit, E. G. (2016). Atypical food packaging affects the persuasive impact of product claims. Food Quality and Preference, 48, 33-40.

Van Rompay, T. J. L., De Vries, P. W., \& Van Venrooij, X. G. (2010). More than words: On the importance of picture-text congruence in the online environment. Journal of Interactive Marketing, 24, 22-30.

Van Rompay, T. J., \& Pruyn, A. T. (2011). When visual product features speak the same language: Effects of shape-typeface congruence on brand perception and price expectations. Journal of Product Innovation Management, 28(4), 599-610.

Vickers, Z., \& Mullan, L. (1997). Liking and consumption of fat-free and full-fat cheese. Food quality and Preference, 8(2), 91-95.

Westerman, D. L., Lanska, M., \& Olds, J. M. (2015). The effect of processing fluency on impressions of familiarity and liking. Journal of Experimental Psychology: Learning, Memory, and Cognition, 41(2), 426-438.

Whittlesea, B. W. (1993). Illusions of familiarity. Journal of Experimental Psychology: Learning, Memory, and Cognition, 19(6), 1235-1253.

Winkielman, P., Schwarz, N., Fazendeiro, T., \& Reber, R. (2003). The hedonic marking of processing fluency: Implications for evaluative judgment. In J. Musch, \& K. C. Klauer (Eds.). The psychology of evaluation: Affective processes in cognition and emotion (pp. 189-217). Mahwah, NJ: Erlbaum.

World Health Organization (2017). Obesity and Overweight Fact Sheet No 311. http:// www.who.int/mediacentre/factsheets/fs311/en/ Accessed 9.11.2017.

Yorkston, E., \& Menon, G. (2004). A sound idea: Phonetic effects of brand names on consumer judgments. Journal of Consumer Research, 31(1), 43-51.

Zajonc, R. B. (1968). Attitudinal effects of mere exposure. Journal of Personality and Social Psychology, 9(2), 1-28.

Zajonc, R. B. (1998). Emotions. In D. T. Gilbert, S. T. Fiske, \& G. Lindzey (Eds.). The handbook of social psychology (pp. 591-632). Boston, MA: McGraw-Hill. 